\title{
Sincalide: A Review of Clinical Utility, Proper Infusion Methodology, and Alternative Cholecystogogues
}

\author{
Harvey A. Ziessman \\ Division of Nuclear Medicine and Molecular Imaging, Russell H. Morgan Department of Radiology and Radiological Science, Johns \\ Hopkins University, Baltimore, Maryland
}

CE credit: For CE credit, you can access the test for this article, as well as additional JNMT CE tests, online at https://www.snmmilearningcenter.org. Complete the test online no later than September 2022. Your online test will be scored immediately. You may make 3 attempts to pass the test and must answer $80 \%$ of the questions correctly to receive $1.0 \mathrm{CEH}$ (Continuing Education Hour) credit. SNMMI members will have their CEH credit added to their VOICE transcript automatically; nonmembers will be able to print out a CE certificate upon successfully completing the test. The online test is free to SNMMI members; nonmembers must pay $\$ 15.00$ by credit card when logging onto the website to take the test.

Sincalide (Kinevac) is widely used in conjunction with cholescintigraphy for a variety of clinical indications. Over the years, numerous publications have verified the optimal infusion methodology. Published data and consensus recommendations emphasize that sincalide, $0.02 \mu \mathrm{g} / \mathrm{kg}$, should be infused over $60 \mathrm{~min}$. Production problems sometimes limit the availability of sincalide. In that case, non-Food and Drug Administration pharmacy-compounded sincalide may serve as an alternative. Fatty meals have also been used. Various illnesses and drugs may inhibit gallbladder contraction. Thus, these drugs should be withheld for $48 \mathrm{~h}$ before the study. Sincalide cholescintigraphy is most commonly used to diagnose or exclude chronic acalculous gallbladder disease. The study should preferably be performed as an outpatient procedure.

Key Words: sincalide; cholescintigraphy; chronic acalculous gallbladder disease; gallbladder; gastrointestinal

J Nucl Med Technol 2019; 47:210-212

DOI: $10.2967 /$ jnmt.119.226019

\section{$\mathbf{S}$} tide hormone analog of cholecystokinin. Its hepatobiliary physiologic effect is to increase bile secretion, cause the gallbladder to contract, and relax the sphincter of Oddi, resulting in bile drainage into the duodenum. There are very few reported side effects, mainly nausea and abdominal cramping when infused too rapidly. The only contraindications are a known allergic reaction to the drug, pregnancy, and intestinal obstruction.

Kinevac is presently the only Food and Drug Administration (FDA)-approved form of sincalide. Unfortunately, it has been commercially unavailable at various times because

Received Jan. 11, 2019; revision accepted Feb. 25, 2019.

For correspondence or reprints contact: Harvey Ziessman, Johns Hopkins

Outpatient Center, 601 N. Caroline St., Suite 3231, Baltimore, MD 21278.

E-mail: hziessm1@jhmi.edu

Published online Apr. 24, 2019.

COPYRIGHT (c) 2019 by the Society of Nuclear Medicine and Molecular Imaging. of production problems. Non-FDA-approved sincalide is available from compounding pharmaceutical companies. These drugs have not been scientifically investigated to confirm equivalence to Kinevac, nor is quality control monitored by the FDA; however, they are commonly used out of necessity when Kinevac is not available. Some hospitals will not permit use of pharmacy-compounded drugs. An alternative formulation of sincalide by another company has been presented to the FDA for approval. If approved, availability should be much improved. Fatty meals are also used as an alternative to sincalide and will be discussed.

\section{CLINICAL INDICATIONS FOR SINCALIDE CHOLESCINTIGRAPHY}

Sincalide cholescintigraphy has been demonstrated to be valuable in a number of clinical situations. It is indicated before cholescintigraphy when the patient has not eaten for $24 \mathrm{~h}$ or is receiving hyperalimentation, to empty the gallbladder of viscous bile that may prevent entry of the hepatobiliary radiopharmaceutical. However, it should be remembered that just because sincalide is given to a patient before the study does not mean that the gallbladder has indeed contracted. Sincalide is also used at some biliary referral centers before cholescintigraphy to diagnose sphincterof-Oddi dysfunction. The rationale for its use is that it increases bile flow, stressing the sphincter of Oddi. Sincalide is also used after routine cholescintigraphy, either to differentiate a partial biliary obstruction from physiologic delayed clearance from the common duct or, most commonly, to diagnose or exclude chronic acalculous gallbladder disease (chronic acalculous cholecystitis). A diseased gallbladder does not contract normally.

Patients with chronic acalculous gallbladder disease typically have symptoms similar to the more common chronic calculous cholecystitis form of the disease, such as recurrent colicky pain in the right upper quadrant, except the patients do not have stones, and thus the diseases is more difficult to diagnose. Sincalide can assist in making this diagnosis. The 
disease has been called by various other names, including cystic duct syndrome, gallbladder spasm, and gallbladder dyskinesia. At pathology these patients' gallbladders have evidence of chronic inflammation identical to patients with the calculous form of the disease.

\section{FATTY-MEAL ALTERNATIVES TO SINCALIDE}

When sincalide is not available, an alternative is needed. It has been suggested that a fatty meal is preferable to sincalide for evaluating gallbladder contraction because it is more physiologic and less expensive; however, there is a potential problem with this approach. Normally, when a healthy person eats a fatty meal, endogenous cholecystokinin is produced in the proximal small bowel and then released systemically, thus producing its physiologic effects. However, if a patient has delayed gastric emptying (gastroparesis), the time required for food to move from the stomach to the duodenum and for cholecystokinin to be released is delayed, sometimes markedly. Thus, the gallbladder may not contract fully during the normal clinical observation time, and a false-positive study (abnormal findings in a healthy patient) may result. The patient's gallbladder may be removed inappropriately, which does not relieve the symptoms.

To produce gallbladder contraction, a meal with more than $10 \mathrm{~g}$ of fat is required. Various fatty meals have been used (1), including but not exclusively Ensure Plus (Abbott Laboratories) (2), milk (3), and corn oil (4). It is imperative to use a meal that has established reference values. With $237 \mathrm{~mL}(8 \mathrm{oz})$ of Ensure Plus, an abnormal gallbladder ejection fraction (GBEF) is less than 33\% (2); for 250 $\mathrm{mL}$ of milk, less than $51 \%$ (3). However, overall data are somewhat limited. Reference values depend on the composition and size of the meal. For patients who can take nothing by mouth, there is really no intravenous alternative. Erythromycin may contract the gallbladder, but there are limited data regarding its use in this situation, appropriate intravenous doses, and reference values.

\section{PROPER INFUSION METHODOLOGY FOR SINCALIDE}

The package insert for Kinevac has not changed since its original FDA approval in the 1960s and states that the drug should be infused over 30-60 s. The rationale was that a bolus infusion was known to potentially cause spasm of the cystic duct, preventing gallbladder contraction. Thus, in the 1980s and early 1990s, numerous nuclear medicine clinics began to infuse sincalide over 3-5 min. A large retrospective study published in 1991 claimed good clinical results with a 3-min infusion (5). Other smaller retrospective studies also claimed good results. Thus, this became a common method of infusion in the United States. However, several other published studies did not find this a useful method for confirming or excluding chronic acalculous gallbladder disease $(6,7)$.

In 1992, a study was published in The Journal of Nuclear Medicine that compared a 3-min infusion with a 30-min infusion in the same healthy subjects (8). With the 3-min infusion of $0.02 \mu \mathrm{g} / \mathrm{kg}$, there was wide variability in results, so much so that reference values could not be calculated. However, when the same patients on another day received a 30-min infusion, it was possible to calculate reference values. A similar study, which was subsequently published in 2001, compared a 3-min infusion with a 60-min infusion (9). Again, reference values were not able to be established with the 3-min infusion because of the wide variability of response in these subjects. However, with the 60-min infusion, reference values could be determined, although they were different from the results of the 30-min infusion in the above study. Importantly, in both studies $50 \%$ of healthy subjects developed nausea or abdominal cramps with the 3-min infusion; however, no subjects had adverse symptoms with either the $30-\mathrm{min}$ or the 60 -min infusion. This result strongly suggests that a short infusion may result in a false-positive clinical patient study, potentially resulting in cholecystectomy when really not indicated or beneficial.

In 2010, a multicenter investigation of 60 healthy subjects was initiated by the Gastrointestinal Council of the SNM (now the General Nuclear Medicine Council of the SNMMI) and published in The Journal of Nuclear Medicine (10). Each healthy subject received 3 different infusions of sincalide, $0.02 \mu \mathrm{g} / \mathrm{kg}$, on separate days, including 15-, 30-, and 60-min infusions. Both the 15-min and the 30 -min infusions resulted in a wide variability in GBEF response, and clinically useful reference values were not able to be determined. However, the 60-min infusion showed much less variability in these same healthy subjects, and clinically useful reference values could be determined. Normal was found to be equal or greater than $38 \%$. With the 15-min infusion, some of the subjects developed nausea or abdominal cramping. This effect was not seen with either the 30-min or the 60-min infusion.

In 2010, the SNM Practice Guideline for Hepatobiliary Scintigraphy stated that the 60-min infusion was the method of choice for sincalide (11). In 2011, the consensus recommendations of an interdisciplinary panel made up of gastroenterologists, surgeons, and nuclear medicine physicians were published in both the gastrointestinal and the nuclear medicine literature. The consensus recommendation was for the 60-min infusion methodology (12).

There is only a single randomized and prospective study in the medical literature that investigated the clinical utility of sincalide cholescintigraphy to predict whether a patient had chronic acalculous gallbladder disease and would have a good response to cholecystectomy (13). The study confirmed its utility. All other studies in the literature are retrospective and considered to be of lesser scientific quality than this prospective study, published by Yap et al. in 1991. They infused sincalide, $0.02 \mu \mathrm{g} / \mathrm{kg} / \mathrm{h}$, over $45 \mathrm{~min}$ but continued imaging through $60 \mathrm{~min}$ and quantifying at $60 \mathrm{~min}$. This method of infusion is slightly different from but actually quite similar to the 60 -min infusion method. These investigators also studied 40 healthy subjects and found a 
normal GBEF to be greater than $40 \%$, again very similar to the $38 \%$ found in the multicenter study described above infusing $0.02 \mu \mathrm{g} / \mathrm{kg}$ over $60 \mathrm{~min}$.

Sincalide cholescintigraphy is best performed as an outpatient procedure when the patient is asymptomatic. Patients in the hospital may have reduced GBEFs due to various reasons other than gallbladder disease, including their acute illness or various medications. Morphine may inhibit gallbladder contraction. When clinicians insist we do a GBEF on inpatients, a normal result is interpreted as diagnostic that gallbladder disease is not the patient's problem; however, an abnormal result is read as indeterminate, and a recommendation is made to repeat the study at a later date as an outpatient procedure. Whatever the clinical indication, sincalide should be infused using the same methodology: a $60-\mathrm{min}$ infusion of $0.02 \mu \mathrm{g} / \mathrm{kg}$.

Despite substantial literature to the contrary, some referring physicians still regard pain and nausea during sincalide infusion to be diagnostic of chronic acalculous gallbladder disease. However, pain during the study is almost always the result of the rate of infusion and not disease per se. Healthy subjects and patients with infusions of 3-15 min may have abdominal discomfort and nausea due to the rate of infusion, but this does not signify disease. And patients who do have chronic acalculous cholecystitis do not have pain during 30- or 60-min infusions.

Various drugs may inhibit gallbladder contraction and should be withheld for $48 \mathrm{~h}$ before the study. The known drugs include opiates and anticholinergic drugs, as well as nifedipine, indomethacin, octreotide, theophylline, benzodiazepines, phentolamine, isoproterenol, and progesterone. Nicotine and alcohol may also inhibit gallbladder contraction and should be avoided before testing.

\section{CONCLUSION}

Sincalide is a valuable pharmacologic intervention with cholescintigraphy, when used appropriately. There are several indications, such as to empty the gallbladder in a patient fasting for more than $24 \mathrm{~h}$ before cholescintigraphy. A common indication is to evaluate a patient for suspected chronic acalculous gallbladder disease. This study should be preferably performed as an outpatient procedure. The method of infusion is important. The recommended method is to infuse $0.02 \mu \mathrm{g} / \mathrm{kg}$ over $60 \mathrm{~min}$. A GBEF of less than $38 \%$ is abnormal. Fatty meals have limitations, particularly in patients with delayed gastric emptying. When used, the specific meal should have well-established reference values.

\section{DISCLOSURE}

No potential conflict of interest relevant to this article was reported.

\section{REFERENCES}

1. Fotos JS, Tulchinsky M. Oral cholecystagogue cholescintigraphy: a systematic review of fatty meal options. Clin Nucl Med. 2015;40:796-798.

2. Ziessman HA, Jones DA, Muenz LR, Agarval AK. Cholecystokinin cholescintigraphy: methodology and normal values using a lactose-free fatty-meal food supplement. J Nucl Med. 2003;44:1263-1266.

3. Xynos E, Pechlivanides G, Zoraas OJ, et al. Reproducibility of gallbladder emptying scintigraphic studies. J Nucl Med. 1994;35:835-839.

4. Bartel TB, Juweid ME, Ponto JA, et al. Corn oil emulsion: a simple cholecystagogue for diagnosis of chronic acalculous cholecystitis. J Nucl Med. 2005;46: 67-74.

5. Fink-Bennett D, DeRidder P, Kolozsi WZ, et al. Cholecystokinin cholescintigraphy: detection of abnormal gallbladder motor function in patients with chronic acalculous gallbladder disease. J Nucl Med. 1991;32:1695-1699.

6. Westlake PJ, Hershfield NB, Kelly JK, et al. Chronic right upper quadrant pain without gallstones: does HIDA scan predict outcome after cholecystectomy? Am J Gastroenterol. 1990;85:986-990.

7. Mishkind MT, Pruitt RF, Bambini DA. Effectiveness of cholecystokinin-stimulated cholescintigraphy in the diagnosis and treatment of acalculous gallbladder disease. Am Surg. 1997;63:769-774.

8. Ziessman HA, Fahey FH, Hixson DJ. Calculation of a gallbladder ejection fraction: advantage of continuous sincalide infusion over the three-minute infusion method. J Nucl Med. 1992;33:537-541.

9. Ziessman HA, Muenz LR, Agarwal AK, Zaza AA. Normal values for sincalide cholescintigraphy: comparison of two methods. Radiology. 2001;221:404-410.

10. Ziessman HA, Tulchinsky M, Lavely WC, et al. Sincalide-stimulated cholescintigraphy: a multicenter investigation to determine optimal infusion methodology and gallbladder ejection fraction normal values. J Nucl Med. 2010;51:277-281.

11. Tulchinsky M, Ciak BW, Delbeke D, et al. SNM practice guideline for hepatobiliary scintigraphy 4.0. J Nucl Med Technol. 2010;38:210-218.

12. DiBaise JK, Richmond BK, Ziessman HA, et al. Cholecystokinin-cholescintigraphy in adults: consensus recommendations of an interdisciplinary panel. Clin Nucl Med. 2012;37:63-70.

13. Yap L, Wychereley AG, Morphett AD, Toouli J. Acalculous biliary pain: cholecystectomy alleviates symptoms in patients with abnormal cholescintigraphy. Gastroenterology. 1991;101:786-793. 